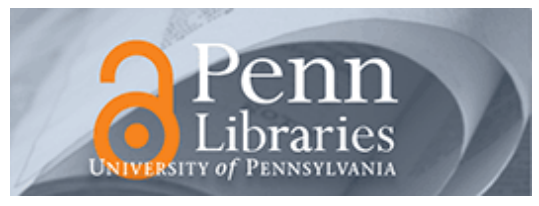

University of Pennsylvania

ScholarlyCommons

Finance Papers

Wharton Faculty Research

$7-2016$

\title{
Service Competition and Product Quality in the U.S. Automobile Industry
}

Jose Guajardo

University of Pennsylvania

Morris A. Cohen

Serguei Netessine

University of Pennsylvania

Follow this and additional works at: https://repository.upenn.edu/fnce_papers

Part of the Econometrics Commons, Finance and Financial Management Commons, and the Operations and Supply Chain Management Commons

\section{Recommended Citation}

Guajardo, J., Cohen, M. A., \& Netessine, S. (2016). Service Competition and Product Quality in the U.S. Automobile Industry. Management Science, 62 (7), 1860-1877. http://dx.doi.org/10.1287/ mnsc.2015.2195

This paper is posted at ScholarlyCommons. https://repository.upenn.edu/fnce_papers/112

For more information, please contact repository@pobox.upenn.edu. 


\title{
Service Competition and Product Quality in the U.S. Automobile Industry
}

\begin{abstract}
We study the impact of service attributes (warranty length, after-sales service quality) on consumer demand in the U.S. automobile industry, examining the presence of complementarities/substitution between service attributes and product quality. Our results estimate a median willingness to pay for one year of a warranty of approximately $\$ 850$, which is equivalent to $3.1 \%$ of the median vehicle price in our sample. We find that, for a car with median characteristics, the effect on consumer utility of a $1 \%$ price decrease is equivalent, all else being equal, to increasing product quality by $2.2 \%$, and is in turn equivalent to increasing the warranty length by $8 \%$. Our results also indicate that service attributes play a compensatory role with respect to product quality; i.e., the impact of warranty length and service quality on demand increases when product quality decreases. Conversely, both service metrics are complementary with respect to demand; i.e., the better the service quality, the higher the marginal effect of longer warranties. Our results thus imply that, in our period of analysis, warranties played a more important role for American firms than for foreign firms, consistent with the fact that American manufacturers exhibited lower product quality and higher service quality than non-American firms.
\end{abstract}

\section{Keywords}

after-sales services, quality, competition, demand, econometrics

Disciplines

Econometrics | Finance and Financial Management | Operations and Supply Chain Management 


\title{
Service Competition and Product Quality in the U.S. Automobile Industry
}

\author{
Jose A. Guajardo \\ University of California Berkeley, iguajardo@berkeley.edu \\ Morris A. Cohen \\ The Wharton School, cohen@wharton.upenn.edu \\ Serguei Netessine \\ INSEAD, serguei.netessine@insead.edu
}

February, 2015

We study the impact of service attributes (warranty length, after-sales service quality) on consumer demand in the U.S. automobile industry, examining the presence of complementarities/substitution between service attributes and product quality. Our results estimate a median willingness to pay for one year of warranty of about $\$ 850$, which is equivalent to $3.1 \%$ of the median vehicle price in our sample. Wend that, for a car with median characteristics, the effect on consumer utility of a $1 \%$ price decrease is equivalent, all else being equal, to increasing product quality by $2.2 \%$, and is in turn equivalent to increasing the warranty length by $8 \%$. Our results also indicate that service attributes play a compensatory role with respect to product quality, i.e., the impact of warranty length and service quality on demand increases when product quality decreases. Conversely, both service metrics are complementary with respect to demand, i.e., the better the service quality, the higher the marginal effect of longer warranties. Our results thus imply that, in our period of analysis, warranties played a more important role for American firms than for foreign firms, consistent with the fact that American manufacturers exhibited lower product quality and higher service quality than non-American firms.

Keywords: Services in Manufacturing; Demand Models; Competition; Automobiles; Econometrics

Electronic copy available at: $\underline{\text { http://ssrn.com/abstract=2065762 }}$

The authors acknowledge financial support from INSEAD and the INSEAD-Wharton Alliance. 


\title{
Service Competition and Product Quality in the U.S. Automobile Industry
}

\author{
Jose A. Guajardo ${ }^{1}$, Morris A. Cohen ${ }^{2}$, Serguei Netessine ${ }^{3}$
}

February, 2015

${ }^{1}$ Haas School of Business, University of California Berkeley, Berkeley, CA 94720, USA, jguajardo@berkeley.edu

${ }^{2}$ The Wharton School, University of Pennsylvania, Philadelphia, PA 19104, USA, cohen@wharton.upenn.edu

${ }^{3}$ INSEAD, 1 Ayer Rajah Avenue, 138676, Singapore, serguei.netessine@insead.edu

\begin{abstract}
We study the impact of service attributes (warranty length, after-sales service quality) on consumer demand in the U.S. automobile industry, examining the presence of complementarities/substitution between service attributes and product quality. Our results estimate a median willingness to pay for one year of warranty of about $\$ 850$, which is equivalent to $3.1 \%$ of the median vehicle price in our sample. We find that, for a car with median characteristics, the effect on consumer utility of a $1 \%$ price decrease is equivalent, all else being equal, to increasing product quality by $2.2 \%$, and is in turn equivalent to increasing the warranty length by $8 \%$. Our results also indicate that service attributes play a compensatory role with respect to product quality, i.e., the impact of warranty length and service quality on demand increases when product quality decreases. Conversely, both service metrics are complementary with respect to demand, i.e., the better the service quality, the higher the marginal effect of longer warranties. Our results thus imply that, in our period of analysis, warranties played a more important role for American firms than for foreign firms, consistent with the fact that American manufacturers exhibited lower product quality and higher service quality than non-American firms.
\end{abstract}

Keywords: Services in manufacturing, demand models, competition, automobiles, econometrics 


\section{Motivation}

A fundamental trend in manufacturing industries is the movement from a "pure manufacturing" paradigm to a business model in which a central role is assigned to the service component of products based on the value they provide to consumers (Cohen et al. 2006). The movement towards a service-based economy has coincided with this change and has encouraged many manufacturing firms to put more emphasis on the delivery of services associated with their product offerings (Shankar et al. 2009). It has been reported that the sales of aftersales services and spare parts represent $8 \%$ of the annual gross domestic product in the U.S. (Cohen et al. 2006). In short, services have become an important part of an OEM's competitive strategy in traditional manufacturing industries. While existing models of product differentiation in manufacturing industries have provided some insights in explaining the consequences of pricing and other product characteristics on demand, they have mostly ignored the impact of services. This paper takes a step in addressing this issue, by formulating an empirical model to analyze the role of services as part of a firm's competitive strategy in the U.S. automobile industry, and the joint effect that service attributes and product quality have on consumer demand.

The automobile industry has served as a preferred setting for empirical studies on product differentiation (e.g. Berry et al. 1995 and 2004, Sudhir 2001, Train and Winston 2007, among many others), and constitutes a natural choice for our research. We focus on services during the in-warranty period. In particular, we measure the service dimension of a brand by the length of its warranty, along with a metric of the after-sales service quality delivered during the in-warranty period. The length of the warranty defines the period in which repair services are provided by the OEM as part of the value that consumers obtain with the purchase of the car, and therefore is a managerial decision that partially reflects the service intensity provided by $\mathrm{OEM}^{1}$. Firms have been active in adjusting the length of their warranties in the last decade: Ford, Chevrolet, Acura, Mazda, Mitsubishi, Audi and Kia are just some examples of brands that have increased the length of their warranties in that period. For example, Ford increased their powertrain warranty from 3 years/36,000 miles to 5 years $/ 60,000$ miles in 2007. In the words of a spokeperson from Ford when asked about the reasons behind the warranty length increase: "We think that some people weren't considering Ford products because we didn't have an extended powertrain warranty versus some of our competition. We hope that it will increase our competitiveness... We think that customers do want it, and do care about it" (Warranty Week 2006). On the other hand, Chrysler

\footnotetext{
${ }^{1}$ We refer to the warranty length as a service attribute because it directly determines the length of the period over which services are delivered and paid for by the manufacturer. It can also be seen as a product attribute that is related to insurance.
} 
and Volkswagen both decreased their warranty length at least once during the same period. Indeed, company sources have suggested that the increase in warranty length by Chrysler for the 2008 model year "wasn't as valuable to consumers as we might have hoped" (Automotive News 2009), and as a result the company cut it back in 2009.

Firms face an important trade-off when defining their warranty period: while longer warranties may potentially increase product demand, they also generate significant costs. For U.S.-based automakers, these costs have typically been in the range of $\$ 10$ billion per year, which represents roughly $2-4 \%$ of their yearly revenue (Warranty Week 2011). This discussion reflects the importance of improving our understanding of the conditions under which warranties and service attributes influence demand.

In this paper we formulate and estimate a model to measure the impact of service attributes on consumer demand in the U.S. automobile industry. Combining data from multiple sources, we propose an empirical model using market-level data for new light cars sold in the U.S. between 2001 and 2007. Our analysis is based on demand formulation that incorporates the two aforementioned variables to characterize firm service strategies, i.e. warranty length and the quality of after-sales service. Our results provide new evidence to explain the influence of warranty length and service quality on the demand for a given model, relative to the influence of other characteristics such as price and product quality. Most existing empirical models of competition in this and other industries deal with the endogeneity of prices while assuming that all other characteristics in the demand specification are exogenous. Our model is different in that we not only endogenize pricing but also the warranty length decision. We do so by generating instruments based on the factors driving firm decision-making for the warranty length. Our findings indicate that, when the endogeneity of warranties is considered, there is a significant effect of warranty length on demand, while service quality does not have a significant effect when this variable is considered in isolation.

We also investigate complementarities and substitution effects between warranty length, service quality and product quality, by conducting a systematic analysis to understand the joint influence of service attributes and product quality on consumer demand. We propose that warranty length, service quality and product quality, interact in a non-trivial way in the consumer's value function, and we investigate the nature of these interactions. In particular, we test whether the effect of service attributes on consumer demand is independent of, or is a complement or substitute for product quality. The theory of compensatory effects in consumer decision-making (e.g. Dieckmann et al. 2009) support the hypothesis that both dimensions act as substitutes, i.e., good service serves the purpose of compensating consumers for poor product quality. Alternatively, service attributes could be complements with product quality if consumers see both dimensions as reinforcing their brand preference, 
i.e., if the primary effect of offering good product quality and good service is to create better brand image.

Our results indicate that the value that consumers derive from warranty length and service quality in the U.S. automobile industry increases when product quality decreases, i.e. service attributes have a bigger impact on demand when product quality is low, providing evidence for a compensatory rather than a complementary role of services relative to product quality. Similarly, we test whether both service attributes have independent, complementary or substitution effects on demand, and find evidence for a complementary relationship in this case. This suggests that a firm that increases its warranty length would make the most out of this investment (in terms of its impact on demand) by simultaneously investing in providing better service quality.

The results of our analysis thus indicate that the joint consideration of product and service is essential for the development of an effective competitive strategy.

\section{Related Literature}

Service competition is a major topic of interest in operations management (OM). In traditional service industries, theoretical models have examined competition when consumer demand depends on price and service levels (So 2000, Cachon and Harker 2002, Allon and Federgruen 2007, Bernstein and Federgruen 2007), and in empirical OM research several studies have tested some of these and related theories in, e.g., the fast food industry (Allon et al. 2011) and the banking industry (Buell et al. 2014). In manufacturing industries, in contrast, service competition has been the subject of theoretical models in OM, e.g., service competition between a manufacturer and a retailer (Cohen and Whang 1997), between retailers that interact strategically with a manufacturer (Tsay and Agrawal 2000), and between manufacturers (Lu et al. 2011). The empirical evidence in the case of manufacturing industries, however, is scarce, and indeed we are not aware of any OM papers that analyze the impact of service competition on consumer demand in manufacturing industries empirically.

In the economics literature, on the other hand, theoretical models of product differentiation (e.g. Shaked and Sutton 1982, Caplin and Nalebuff 1991), have prompted numerous empirical studies, especially in the automobile industry where researchers have studied different aspects of firm competition and consumer demand (e.g. Berry et al. 1995, Train and Winston 2007, among many others). Similar to the OM literature, these economic models of demand have omitted the role of supporting services by automakers.

Our paper thus attempts to fill this gap by analyzing the role of service attributes as drivers of consumer demand in the U.S. automobile industry. Moreover, as our results illus- 
trate, considering the interaction between service attributes and product quality is essential in order to disentangle the effects of service attributes on demand in this industry, and thus analyzing service competition in a manufacturing industry offers new evidence that goes beyond what has been done in service industries. One particular advantage that is gained by incorporating product and service dimensions into a single analysis is that it allows us to examine the existence of complementarities and substitution effects. As we discuss in the paper, we are not aware of other papers that have looked at studying such interaction effects in a competitive market. We believe this novel feature of our model also connects operations variables related to quality to the competitive strategy of the firm which includes product/service bundle positioning. Further, some survey-based studies in the automobile industry have suggested that service quality plays a role in determining customer satisfaction and brand loyalty (e.g., Mittal et al. 1999, Devaraj et al. 2001), but we are not aware of research that focuses on the impact of service attributes on consumer demand in manufacturing industries and in a competitive context, and how that effect of service attributes on demand depends on characteristics of the product.

One of the service variables we focus on is length of warranty. Four main rationales regarding the economic role of warranties have been proposed in the literature (see e.g. Emons 1989 for a comprehensive discussion): protection against product failures (insurance role), provision of product quality information to consumers (signaling role), a mechanism to discriminate consumer risk preferences if customer heterogeneity is not fully observable by the seller (sorting role), and to incentivize the seller to improve product quality (incentives role). These theories would thus be consistent with consumer preferences for longer warranties, all else being equal. Regarding the insurance role (e.g. Heal 1977), warranties provide consumers with some security against poor product quality and are often used by manufacturers as a value-added feature to promote their products (Thomas 2006). The signaling argument, on the other hand, predicts that higher quality products will have longer warranties, and is perhaps the one that has received the most attention. Since Spence's model of perfect competition in which warranties serve as signals of reliability (Spence 1977), several theoretical models have qualified this finding in alternative settings (e.g. Cooper and Ross 1985, Gal-Or 1989).

Empirical tests of the signaling role of warranties are also numerous. While early papers like Wiener (1985) showed a positive association between warranty length and product quality providing support for the signaling argument, others like Douglas et al. (1993) showed that the opposite is possible. More recently -and more broadly- Chu and Chintagunta (2011) empirically tested for the different roles of warranties in the U.S. automobile and PC server industries, finding support for the insurance and sorting role of warranties, but not for the 
signaling and incentives roles. Given the numerous papers studying the economic role of warranties, we do not address this question and rather build our model upon some of the findings in this literature, to study how service attributes such as warranty length and service quality, along with product quality, jointly influence consumer demand.

Empirical models of demand related to ours that include consumer response to warranties include Menezes and Currim (1992) and Chu and Chintagunta (2009). Menezes and Currim (1992) formulate a theoretical model to define the appropriate warranty length for firms, and they also perform some empirical testing in the automobile industry. Their empirical analysis is based on a sales response model (aggregate demand function), for which OLS analysis is performed, and in which several attributes are used to explain total sales for a given model. They do not deal with the endogeneity of either the price or the warranty length in the demand specification. In a paper more closely related to our study, Chu and Chintagunta (2009) empirically analyze the value of warranties in the U.S. server market. Their research in this $\mathrm{B} 2 \mathrm{~B}$ setting quantifies the value of warranties for manufacturers, intermediaries and customers, and finds a positive value for warranties in all cases. As in our analysis, their demand model is based on a random coefficients logit model that allows for customer heterogeneity and that is based on market data, but they only account for the endogeneity of the pricing decision.

While past empirical studies are certainly relevant for our analysis, we establish at least three important differences. First, these papers focus on warranties exclusively, while our interest is in services more broadly defined, which includes not only the firm's warranty length but also its service quality in the demand specification. Second, our focus is on understanding the effect on demand of the interaction between service attributes and product quality. To our knowledge, our findings in this regard have not been established in previous empirical literature. Third, from a methodological perspective, unlike past papers, note that we explicitly deal with the endogeneity of both pricing and warranties, and our identification strategy for warranty effects could be used in other settings ${ }^{2}$.

With respect to the third aspect, most existing models of product differentiation have accounted for the endogeneity of prices in the demand specification, under the assumption of exogeneity of all other product characteristics. This assumption has been recognized as an important shortcoming in this literature (Berry 1994). As a response, a recent and growing stream of research on endogenous product choice has considered models in which some product characteristics other than price are treated as endogenous (see Crawford 2012 for a review of this research stream, or Fan 2013 for a recent example). Our research thus

\footnotetext{
${ }^{2}$ See section 4.2 for a discussion of the required assumptions under which our identification strategy is valid, and sections 5.4 and 6 for discussion of limitations of our strategy.
} 
also relates to the endogenous product choice literature, as we deal with the endogeneity of both pricing and the warranty length decision by firms. Finally, our research is related to the numerous empirical studies in OM that examine the automobile industry, including Fisher et al. (1999), Ramdas and Randall (2008), Cachon and Olivares (2010), and Gallino et al. (2013), among many others, that as ours attempt to examine some aspect that contribute to an understanding of factors influencing the matching between what firms supply and what consumers demand in this industry.

In short, this paper contributes to the aforementioned streams of research by being one of the first to empirically analyze the value of service attributes as drivers of demand in manufacturing industries, and by being (to our knowledge) the first study to empirically analyze the complementarity and substitution between service attributes and product quality in the context of demand models in a competitive manufacturing setting. Product quality, service quality and warranty length are variables of longstanding importance in OM research. The new empirical evidence of their impact on demand in a competitive setting provided in this paper, contributes to a better understanding of the strategic implications of the joint management of these variables by firms.

\section{Data and Industry Background}

Market-level data was collected from different sources for our analysis. We obtained data on sales and product characteristics from Ward's Automotive, for all new light cars sold in the U.S. in the period 2001-2007. Vehicle specifications include miles-per-gallon, length, width, height, horsepower and weight, among other features. Data about warranty length were obtained from the 2009 Official Warranty Guide (J\&L Warranty Pros). Data on product quality and service quality at the brand level were obtained from J.D. Power's Initial Quality Study and Costumer Service Index. Aggregate yearly data on transactional prices were obtained from a secondary source, based on J.D. Power data. Below, we discuss some characteristics of these data sources in more detail, along with aspects of the industry that help to clarify our analysis.

Warranty data: Automakers include manufacturer warranties bundled with the purchase of every new car, to protect consumers against defects for a certain period of time/usage. The most relevant warranties bundled with a new car are the basic warranty (which covers most parts of a vehicle), and the powertrain warranty (which covers the major cost components of the car such as the engine, transmission, etc., usually for an extended period of time). For example, the Acura 2007 model year vehicles had basic and powertrain warranties of 4/50,000 and 6/70,000 [years/miles], respectively. For a given brand, there is a high cor- 
relation between the warranty terms for these two types of warranties (indeed, for several brands the coverage period is often the same for basic and powertrain warranties), and also between the years/miles metrics.

Most of the existing studies on warranties have focused on the duration of the powertrain warranty for several reasons. First, the powertrain warranty covers the most expensive parts of the vehicle. Second, most of the changes in warranty strategies by OEM's refer to powertrain warranty duration and therefore is the richer source of longitudinal variation. There were 25 longitudinal changes for the powertrain warranty during our observation periods, but only 7 if we look at basic warranties. Examples of changes in powertrain warranties include Kia from 5/60,000 to 10/100,000 in 2001, Mazda from 3/50,000 to 4/50,000 in 2003, Mitsubishi from 5/60,000 to 10/100,000 in 2004, Acura from 4/50,000 to 5/70,000 in 2006, and Chevrolet from 3/36,000 to 5/100,000 in 2007, among several others. Finally, the powertrain warranty is the warranty that automakers advertise the most. Consistent with these arguments, we use the length of the powertrain warranty in years as our warranty variable.

Quality data: J.D. Power publishes yearly reports on product quality and service satisfaction at the brand level. Here we provide a brief description of the data used in our analysis, further details can be obtained via http://www.jdpower.com/.

Our product quality metric is based on J.D. Power's Initial Quality Study (IQS), which determines the number of problems per 100 vehicles in the first 90 days of ownership. The study examines 217 vehicle attributes, and reports on a broad range of problems reported by owners, including defects/malfunctions (complete breakdown or malfunction of any component, feature, or item) and design problems (components or features that may be functioning as designed, but are perceived to be difficult to use or understand, or are in a poor location). Every year this information is summarized in a brand-level metric. For example, in 2004 the best brand was Lexus with 87 problems per 100 vehicles, the worst was Hummer with 173 problems per 100 vehicles, and the industry average was 119 problems per 100 vehicles. We take the negative of the number of problems per vehicle as our product quality metric $P Q_{b t}$, such that a higher value for $P Q_{b t}$ (smaller number of problems per vehicle) denotes higher product quality.

Similarly, J.D. Power's Customer Service Index (CSI) measures the satisfaction of vehicle owners who visited the dealer service department for maintenance or repair work during the first three years of ownership. According to the J.D. Power's description, the CSI study "provides an overall customer satisfaction index score based on six measures: service initiation, service advisor, in-dealership experience, service delivery, service quality, and user-friendly service." The score is based on a 1000 point scale. For example, in 2004 the best brand was Lincoln with a score of 912 , the worst was Daewoo with a score of 754 , and the industry av- 
erage was 862 . We note that this metric refers to after-sales service at dealers during the first three years of ownership, which is coincident with the minimum warranty period observed in the industry. This metric thus reflects services that occurred during the in-warranty period, and in conjunction with the warranty length, defines the variables that we use to characterize the service dimension of a brand. Specifically, our service quality variable $S Q_{b t}$ is a scaled version of the customer service index (CSI score/1000).

We note several interesting observations. Pooling the data for our period of analysis at the brand level (2001-2007), we obtain a correlation of 0.64 between $P Q_{b t}$ and $S Q_{b t}$, denoting a positive relationship between product quality and service quality. As illustrated in Figure 1 , most brands are located on the diagonal of the graph. The graph from 2004 suggests some exceptions, like Saturn (low product quality, high service quality), and Hyundai and Toyota (high product quality, low service quality). Similarly, we obtain correlations of - 0.13 between warranty and PQ, and -0.29 between warranty and SQ. These statistics reflect a negative correlation between warranty length and both product quality and service quality. Note that the fact that we don't find a positive correlation between warranty and product quality provides some descriptive evidence that counters the signaling role of warranties. Figure 1 displays the relationship between our warranty (WARR), product quality (PQ), and service quality (SQ) metrics for 2004 for the brands in our sample.

Finally, we note that, while the service experience at dealers is not fully determined by OEM, they can and do influence the service process in several ways. First, OEM impose guidelines and service standards on their dealers. Second, they can facilitate the quality of service delivered by dealers through a wide range of managerial interventions, e.g., by setting up parts pooling mechanisms, sharing information, using vendor-managed inventory and implementing a generous parts return policy for dealers. Third, OEM usually set up incentive programs, whereby a dealer's compensation is, in part, based on service performance. Finally, the design of the service network, for example, the definition of the number of dealers, is ultimately defined by the OEM. As an illustration, consider e.g. the evidence discussed in Cohen et al. (2000), where persistent brand-level differences in after-sales services is documented e.g. with respect to parts availability for repair services by different brands, as well as with respect to mechanisms for information sharing and distributed service systems employed in Saturn's service supply chain, in contrast to industry standards at the time ${ }^{3}$.

\footnotetext{
${ }^{3}$ Naturally, when it comes to after-sales services, it is clear that in practice some important variation would occur at the dealer level, not only at a brand level. Dealer-level metrics would potentially provide richer variation, in contrast to the low level of variation we observe in our brand-level metrics (Table 1). However, as we argue, there are a number of decisions that are taken at the OEM level, which supports the perspective we adopt in our study. For further details about dealer/OEM interactions, we refer the reader to Cohen et al. (2000) for service aspects, and to Cachon and Olivares (2010) for more general aspects.
} 


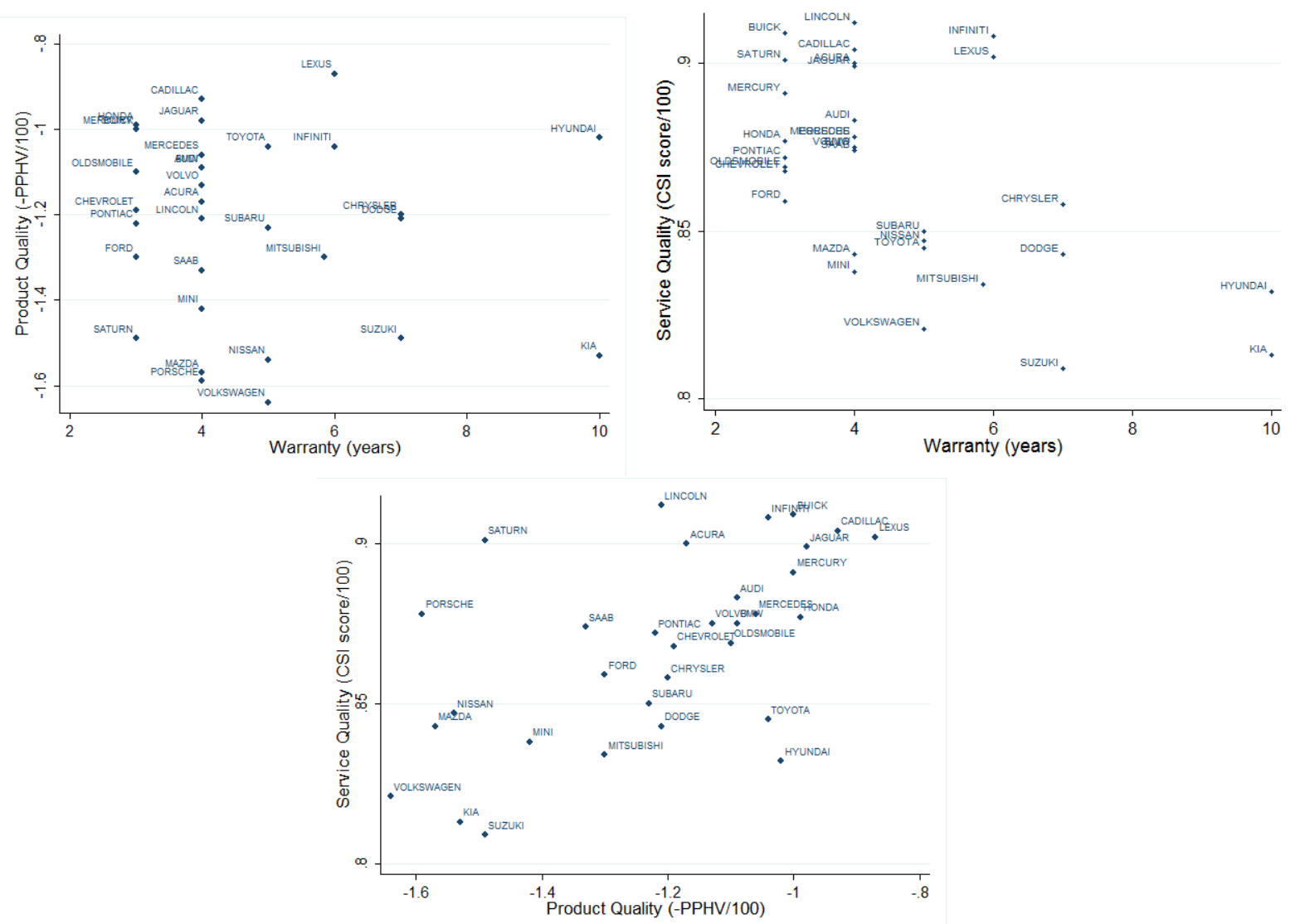

Figure 1: Visualization of Warranty, Service Quality and Product Quality (2004)

Sales, prices and product characteristics: We obtained data on sales and product characteristics from Ward's Automotive for all new light cars sold in the U.S. between 2001 and 2007. This includes cars belonging to the segments small, middle, large and luxury, as categorized by Ward's. Sales data is available at the make-model level (e.g. Toyota Corolla) monthly. Data on product characteristics is available for each model year and for each of the versions of a given make-model. Several vehicle-level variables are of interest. First, the size of the car (SIZE) was measured as the product between the length and the width. The ratio of horsepower to weight (HPWT) is self-descriptive. We also constructed the variable miles per dollar (MPD), obtained by dividing the miles-per-gallon by the dollarsper-gallon in a given year. We obtained monthly average prices for gasoline from the U.S. Department of Energy (http://www.eia.doe.gov), which are aggregated at the calendar year level to calculate the MPD variable. Fuel prices are expressed in 2007 dollars using the CPI index for the respective year, and the same is done for the vehicle price $p_{j t}$ (PRICE), i.e., all monetary variables in our analysis are expressed in 2007 dollars (data on CPI's were obtained from the U.S. Department of Labor, Bureau of Labor Statistics, available at http://www.bls.gov/cpi/cpirsdc.htm). As noted in existing studies (e.g. Berry et al. 1995, 


\section{Table 1: Descriptive statistics}

\begin{tabular}{lllll}
\hline Variable & Mean & Std. Dev. & Min & Max \\
\hline PRICE $(\$ 1,000)$ & 34.938 & 22.161 & 10.286 & 170.689 \\
WARR (years) & 4.7 & 1.9 & 3 & 10 \\
PQ (-1 x problems per vehicle) & -1.289 & 0.235 & -2.670 & -0.760 \\
SQ (CSI score/1000) & 0.863 & 0.032 & 0.781 & 0.925 \\
MPD ([miles/\$]/10) & 1.028 & 0.336 & 0.439 & 3.770 \\
HPWT $(100 \mathrm{x} \mathrm{hp} / \mathrm{lb})$ & 0.643 & 0.171 & 0.203 & 1.578 \\
SIZE (sq. inches $/ 10,000)$ & 1.314 & 0.145 & 0.792 & 1.708 \\
\hline
\end{tabular}

Sudhir 2001), a certain level of aggregation is required to match sales data with the respective product characteristics. For a given product characteristic, e.g. size, we consider the average size of the options of a given model year as the size associated with that model year (an approach also taken by Balachander et al. 2009).

In addition, we obtained yearly data on transactional prices at the make-model by model year level from a secondary source based on J.D. Power data. These data are collected at the daily level by J.D. Power from a sample of dealers in the U.S. covering about $70 \%$ of the geographical areas and 15-20\% of total U.S. sales. These data reflect transactional prices paid by consumers after rebates and as such, are more informative of actual consumer expenses than the manufacturer suggested retail price which is usually used in research papers due to the unavailability of information about transactional prices. We only have access to these data at the aggregate yearly level, more precisely, the average across time of the transactional prices paid by consumers for a given make-model by model year in the period SeptemberAugust of each year, which is the definition used for calendar year in our analysis. Note that sales data from Ward's do not distinguish between different model years of a given makemodel sold in the same calendar year. In practice, however, in a given calendar year different model years of the same make-model are sold simultaneously. The pricing data set contains sales at the model year level for each calendar year for the sample of dealers described above. We use the distribution of sales in this data set and apply it to the market level sales data from Ward's to obtain sales at the make-model by model year level. A similar approach to matching both data sets was taken by Copeland et al. (2011).

Sample: We match all data sources as described above. Our final sample consists of 2122 yearly observations for all new light cars sold in the U.S. in calendar years 2001-2007, which includes model years from 2000 to 2008. Our unit of analysis is a make-model by model year and calendar year, e.g. 2005 Toyota Corolla in calendar year 2005. Table 1 displays descriptive statistics for the relevant variables in our sample of 2122 observations, including statistics for the warranty length (WARR), product quality (PQ), and service quality (SQ). 
Table 2: Correlation Matrix

\begin{tabular}{llllllll}
\hline Variable & PRICE & WARR & PQ & SQ & MPD & HPWT & SIZE \\
\hline WARR & $-0.19^{* * *}$ & & & & & \\
PQ & $0.29^{* * *}$ & $-0.10^{* * *}$ & & & & \\
SQ & $0.26^{* * *}$ & $-0.24^{* * *}$ & $0.66^{* * *}$ & & & \\
MPD & $-0.39^{* * *}$ & 0.02 & $-0.18^{* * *}$ & $-0.41^{* * *}$ & & & \\
HPWT & $0.76^{* * *}$ & $-0.18^{* * *}$ & $0.24^{* * *}$ & $0.30^{* * *}$ & $-0.56^{* * *}$ & & \\
SIZE & $0.28^{* * *}$ & $-0.22^{* * *}$ & $0.21^{* * *}$ & $0.32^{* * *}$ & $-0.44^{* * *}$ & $0.24^{* * *}$ & \\
\hline Note: ${ }^{* *},{ }^{* *}, * * *$ & Significant at the $0.1,0.05,0.01$, confidence levels, respectively.
\end{tabular}

Table 2 displays the correlation matrix for these variables.

\section{Model}

\subsection{Demand model formulation}

We consider a random coefficients logit demand model, where the utility that consumer $i$ derives from purchasing vehicle model $j(j=1, \ldots, J)$ of brand $b(b=1, \ldots, B)$ in calendar year $t(t=1, \ldots, T)$ depends on the vehicle price $p_{j t}$, a vector of observable vehicle characteristics (size, horsepower to weight ratio, etc.) $x_{j t}$, warranty duration $w_{b t}$, product quality $P Q_{b t}$, service quality $S Q_{b t}$, other brand-level variables $x_{b t}$, as follows:

$$
u_{i j t}=\alpha_{i} p_{j t}+x_{j t}^{\prime} \beta_{i}+h\left(w_{b t}, P Q_{b t}, S Q_{b t}\right) \gamma+x_{b t}^{\prime} \eta+\xi_{j t}+\epsilon_{i j t}
$$

The term $\xi_{j t}$ represents unobserved product attributes common to all consumers, and $\epsilon_{i j t}$ is a type I extreme value idiosyncratic shock. Consumers maximize utility, and purchase vehicle $j$ in calendar year $t$ if and only if $u_{i j t} \geq u_{i r t}$ for all $r=0,1, \ldots, J$. Here, $r=0$ defines the outside good, i.e., the option of not purchasing a new light car in year t, where $u_{i 0 t}=\epsilon_{i 0 t}$. The individual-level coefficients $\alpha_{i}$ and $\beta_{i}$ are decomposed into a mean effect common to all consumers $\left(\beta^{\prime} s\right)$ and individual deviations from that mean $\left(\sigma^{\prime} s\right)$. The total effect of attribute $x_{j t}^{k}$ on the utility of consumer $i$ is thus modeled as $\left(\beta_{k}+\sigma_{k} v_{i k}\right) x_{j t}^{k}$, where $\beta_{k}$ and $\sigma_{k}$ are parameters to be estimated, and $v_{i k}$ is an individual-level shock obtained from a standard normal distribution; the same holds for $\alpha_{i}$. It is useful to note that $u_{i j t}$ can be thus expressed more compactly as a function of the mean utility $\delta_{j t}$ common across all consumers, and the heterogeneity terms $\mu_{i j t}$ and $\epsilon_{i j t}$ as:

$$
u_{i j t}=\delta_{j t}\left(p_{j t}, x_{j t}, w_{b t}, P Q_{b t}, S Q_{b t}, x_{b t} ; \theta_{1}\right)+\mu_{i j t}\left(p_{j t}, x_{j t}, v_{i} ; \theta_{2}\right)+\epsilon_{i j t}
$$

Here, $\theta_{1}$ is a vector containing all parameters of the mean utility $(\alpha, \beta$, and $\gamma)$, and $\theta_{2}$ contains the heterogeneity parameters $(\sigma)$. Let $d_{j t}$ contain all $M$ vehicle characteristics 
involved in the heterogeneity estimates. Thus $\delta_{j t}$ and $\mu_{i j t}$ are defined as:

$$
\begin{gathered}
\delta_{j t}=\alpha p_{j t}+x_{j t}^{\prime} \beta+h\left(w_{b t}, P Q_{b t}, S Q_{b t}\right) \gamma+x_{b t}^{\prime} \eta+\xi_{j t} \\
\mu_{i j t}=\sum_{m=1, \ldots, M} \sigma_{m} d_{j t}^{m} v_{i m}
\end{gathered}
$$

The function $h\left(w_{j t}, P Q_{j t}, S Q_{j t}\right)$ defines the way in which warranty length, product quality and service quality enter into the utility function. Under the linearity assumption for these variables, the utility function takes the following form:

$$
u_{i j t}=\alpha_{i} p_{j t}+x_{j t}^{\prime} \beta_{i}+\gamma_{1} w_{b t}+\gamma_{2} P Q_{b t}+\gamma_{3} S Q_{b t}+x_{b t}^{\prime} \eta+\xi_{j t}+\epsilon_{i j t}
$$

This formulation is useful to capture the main effects of the variables of interest, and is also consistent with the linearity assumption made for the rest of the covariates. We refer to the model derived from the utility function in Eq. 5 as the main effects model.

We are also interested in testing, however, whether service attributes and product quality act as complements, substitutes or independently in the demand function. For this purpose, we consider an enhanced formulation in which the function $h\left(w_{b t}, P Q_{b t}, S Q_{b t}\right)$ not only includes the main effects for these three variables -as described in Eq. 5- but also their interaction terms $w_{b t} * P Q_{b t}, w_{b t} * S Q_{b t}$, and $P Q_{b t} * S Q_{b t}$. These interactions reflect the non-linearities of interest, i.e., the complementarity/substitution effects between service attributes and product quality.

At this regard, a recent study by Guajardo and Cohen (2015) has shown that service quality and product quality perceptions act as complements in terms of how they determine the likelihood to recommend the brand in an application in the consumer electronics industry. In their study, they focus on brand loyalty by customers and they find that the better the perceptions of product quality of a person, the higher the impact of better perception about service quality on the person's likelihood to recommend the brand. Their results are based on a sample of existing customers of one major brand, in contrast to this paper in which we focus on the whole market and cover all brands under competition. In the context of our demand model, we would expect service attributes and product quality also to be complements if the dominating mechanism by which they affect consumer demand is through their impact on brand image. A related argument can be proposed in support of the complementarity hypothesis. If higher product quality creates higher utility and enjoyment for drivers, receiving good service (e.g., cars repaired more quickly and smoothly) could be more valuable for cars with higher product quality (if they serve the basic need of transport 
with value added in terms of driving experience), relative to a lower quality car (if it only satisfies the basic need of transport).

On the other hand, service attributes could act as substitutes for product quality if the main mechanism by which they affect consumer demand is by compensating consumers for poor product quality, i.e., if the car purchase process can be described as a compensatory process with respect to these attributes. In a compensatory decision process (e.g., Dieckmann et al. 2009), strengths along one or more dimensions of product or service quality can compensate for weaknesses along others. This is in contrast to the case of non-compensatory processes, in which no compensation is possible if certain attributes of a product or service are weak, even if it possesses strengths along other dimensions. The role of compensatory effects in consumer decision-making would thus provide a basis for characterizing our service attributes as substitutes for product quality.

Similar arguments can be hypothesized for the interaction between warranty and service quality, i.e., a negative interaction under the hypothesis of compensatory attributes, or a complementary (positive) relationship not only if they both contribute to better brand image, but also if the main mechanism by which they affect consumer demand is by providing complementary functionality (longer and better service support). In the case of warranties and product quality, their insurance role (Heal 1977, Emons 1989) implies that warranties should be more important for consumers when the product is expected to fail more often, i.e., when product quality is lower, which would provide additional support for the hypothesis of a negative coefficient for the term $w_{b t} * P Q_{b t}$.

Alternatively, all three attributes may exhibit independent effects on consumer decisionmaking, in which case no significance would be obtained for the interaction terms. In this scenario of competing theories, whether service attributes act as complements, substitutes, or independent of product quality in the demand function is ultimately an empirical question, which we attempt to answer in this study.

\subsection{Identification and instruments}

In practice, most of the observed variables in our demand specification are determined or influenced by firm's decisions. On the other hand, $\xi_{j t}$ reflects characteristics or shocks not observed in the data, such as style, prestige, and reputation, that affect the demand for different products. An endogeneity problem for the demand parameters emerges if some of the observed variables are set by firms upon observing the demand shocks $\xi_{j t}$. As noted, most existing studies have accounted for the endogeneity of prices in the demand specification under the assumption of exogeneity for all other product characteristics. More precisely, the mean independence condition $E[\xi \mid x]=0$ is assumed for all exogenous $x$. While the exogene- 
ity assumption for non-price characteristics has been widely acknowledged as a shortcoming since Berry (1994), the underlying argument for it relies on the fact that, while the prices are easily adjustable by firms according to the market conditions and therefore $p_{j t}$ is likely to be correlated with $\xi_{j t}$ (i.e., price endogeneity), other product characteristics captured by $x_{j t}$ (e.g., horsepower, size) are defined by firms well in advance of the time when a model is sold in the market, and thus are assumed to be uncorrelated with $\xi_{j t}$.

To account for the endogeneity of prices, instrumental variables can be used in the estimation. A well-known example is Berry et al. (1995)'s model for the auto industry involving prices $p_{j t}$ and product characteristics $x_{j t}$ in the demand specification. Their supply model considers firms competing on prices, and makes a Bertrand-Nash equilibrium assumption. Under these assumptions, they propose a set of instruments to deal with price endogeneity: the sum (or average) of product characteristics $x_{j t}$ for (i) other cars of the same firm, and (ii) cars of other firms. Product characteristics $x_{j t}$ are exogenous by assumption, and are thus also used as instruments. This set of instruments has been widely used to deal with price endogeneity since then (e.g., Sudhir et al. 2001, Train and Winston 2007, Balachander et al. 2009). We use this set of instruments to deal with price endogeneity; as in Sudhir (2001), instead of considering the average characteristics for cars of all other firms, we compute the average characteristics of other firms' cars in the same market segment (small, middle, large, luxury), which refines the set of instruments by using cars that are closer to each other in terms of characteristics.

Our specification of the demand model involves not only prices and vehicle characteristics, but also brand level attributes $w_{b t}, P Q_{b t}$, and $S Q_{b t}$. In principle, firms can easily set the length of the warranty $w_{b t}$ in response to the unobserved factors in $\xi_{j t}$. A similar observation was made by Menezes and Currim (1992), who noted that in contrast to changes in product quality, changes in warranty length and price could be carried out almost instantaneously ${ }^{4}$. Thus, warranties are expected to be endogenous in the demand specification.

Conversely, let us consider firm actions to influence $P Q_{b t}$ and $S Q_{b t}$. Note that firms can affect product quality by introducing changes in product design, using better parts/components (Ramdas and Randall 2008), redesigning their processes, etc. All of these factors will be reflected over a term longer than our yearly period of analysis. The time-to-market of a vehicle, for example, can take several years from the beginning of the design stage to product launch. Similarly, factors influencing service quality such as the implementation of optimizationbased technologies for the management of parts inventories, the design of a more efficient

\footnotetext{
${ }^{4}$ Of course, consistent with the observed data, in practice there are reasons that could prevent firms from adjusting warranties too frequently. For example, firms wanting to decrease warranty length as a response to a negative warranty cost shock may opt for not doing so due to potential detrimental impact on brand image.
} 
service network, and a higher focus on services more generally, will usually involve long-term efforts and cultural changes by firms (see, e.g., Cohen et al. 2000). We thus assume that the observed $P Q_{b t}$ and $S Q_{b t}$ are not easily adjustable contemporaneously by firms upon observing the shocks $\xi_{j t}$, and therefore will consider $P Q_{b t}$ and $S Q_{b t}$ to be exogenous in the demand specification. This is our main identification assumption.

We assume therefore that firms compete on prices and warranties. This assumption is consistent with some prior theoretical models (e.g., Spence 1977, Gal-Or 1989), which have modeled competition based on these two variables, taking other factors such as product quality as given. As noted, by offering warranties, firms incur important warranty costs $w c_{j t}$. In order to illustrate our instruments, it is useful to expand on the drivers of the warranty costs for firms.

Generically, let $N(t)$ be the stochastic process for the number of failures of a vehicle by time $t$, and $Y_{n}(t)$ the cost of failure $n$ at time $t$, independent of $N(t)$. A standard formulation for expected warranty costs (e.g., Thomas 2006 pp. 67) if the warranty length is set to W is thus $w c(W)=E\left[\sum_{n=1, \ldots, N(W)} Y_{n}(t)\right]$. If the time between failures is iid, the expected warranty costs are given by $w c(W)=E[N(W)] E\left[Y_{n}(t)\right]$. The term $E[N(W)]$ represents the expected number of failures during the warranty period, which depends on the warranty length and the failure process. For example, if $N(t)$ is assumed to be a homogeneous Poisson process and $\lambda$ is the failure rate per time unit, then $E[N(W)]=\lambda W$; if the failure process is more complex, in general $N(t)$ will not necessarily have a tractable closed-form solution. For our purposes (and using our notation), however, it suffices to note that $E[N(W)]$ is a function of product quality $P Q_{j t}$ and the warranty length $w_{j t}$. With respect to the expected cost per event, $E\left[Y_{n}(t)\right]$, we must consider heterogeneity across brands. In particular, and in line with the previous literature (e.g. Cohen and Whang 1997), providing a certain level of service quality is costly, and thus the cost per event will depend on the quality of service provided when servicing the vehicle, for which our $S Q_{j t}$ variable can serve as a proxy. Let $x b_{j t}$ denote other observable characteristics that capture part of the brand heterogeneity in warranty costs, and $\varsigma_{j t}$ unobservable factors. The warranty costs function $g$ can be thus represented conceptually as:

$$
w c_{j t}=g\left(w_{b t}, P Q_{b t}, S Q_{b t}, x_{b t}, x_{j t}, \varsigma_{j t}\right)
$$

We derive instruments for the warranty length based on the exogeneity assumption for $P Q_{b t}, S Q_{b t}$, and for product characteristics other than price and warranty more generally, and our supply side assumption (with competition on prices and warranties only), as follows. Consider vehicles $i$ and $j$, produced by brands $q$ and $r$ respectively $(q \neq r)$. Note that given our assumption that firms compete on prices and warranties, $w_{q t}$ and $w_{r t}$ are the result of 


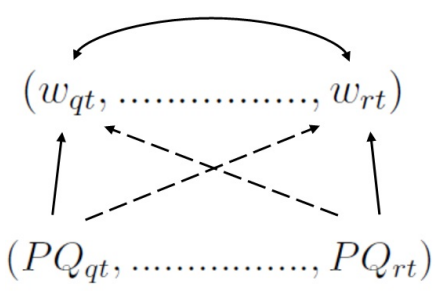

Figure 2: Instruments

the strategic interaction of firms and are therefore correlated. If firms set their warranties optimally (or at least, take into account the expected warranty costs), $w_{q t}$ will be correlated with the drivers of warranty costs, e.g., $P Q_{q t}$ (see Eq. 6). Similarly, $w_{r t}$ will be correlated with $P Q_{r t}$. Noting that $u_{i j t}$ depends only on vehicle $i^{\prime} s$ attributes, then $P Q_{r t}$ (attribute of vehicle $j$ ) is a valid (source of) instruments for $w_{q t}$ (attribute of vehicle $i$ ). We thus consider the average of product quality of other brands as an instrument for the warranty of a given brand.

We apply this same argument to generate instruments using the rest of the drivers of warranty costs, i.e., $S Q_{b t}$ and $x_{b t}$ (Eq. 6). In $x_{b t}$ we include dummies for the region of the manufacturer (coded into three categories: USA, Europe, Asia) to partially capture heterogeneity across brands. Thus, our set of instruments for warranties includes the average product quality of other brands, the average service quality of other brands, and the proportion of brands belonging to the different geographical regions. To further explain the logic behind these instruments, warranty definitions by a brand should consider the brand's product quality and service quality. Since in our model the warranty length is the result of strategic interaction among firms, product quality and service quality of competing brands thus indirectly influence the warranty choice for a brand. This mechanism justifies the relevance of our proposed IV's of average product quality and average service quality by other brands.

Exogeneity of these IV's follows from the assumption of the exogeneity of product quality and service quality and from the fact that the utility obtained from a given product does not depend on other products' characteristics (recall that we require the mean independence assumption $E[\xi \mid x]=0$ for all exogenous variables $x)$. Note that heterogeneity at the vehicle model level is already captured through the $x_{j t}$-based instruments. Finally, since 2003 it has been mandatory for firms traded in the U.S. to disclose warranty costs in their financial statements, which was private information before that. This modifies the information set under which firms make their warranty decisions and, being unrelated to the demand side, may thus serve as additional source of exogenous variation to instrument for warranties. We thus construct an indicator function (pre vs. post 2004 calendar year) and include it as an 
additional instrument.

Finally, note that we observe cross-sectional and longitudinal price variation for all models and years, as well as for product quality and service quality for all brands and years. Although the variation in warranties is more limited (e.g., it does not allow us to include brand fixed effects in the demand specification), we do observe cross-sectional variation across brands in our warranty variable each year and longitudinal variation for several brands at some point in our observation period. For some of these brands with longitudinal changes we also observe variation in warranty length for different model years of the same make-model being sold in the same calendar year. Finally, there is variation in the observed warranties in the market (as well as in the rest of the variables) due to changes in the choice set of vehicles available in the market each year. Also note that, along with the warranty length, we include other brand-level variables in the demand specification (product quality, service quality, and manufacturer geographical region), which partially alleviates concerns about brand fixed effects as potential confounders ${ }^{5}$.

\subsection{Estimation}

The estimation of random coefficients demand models is discussed in detail in Berry (1994), Berry et al. (1995), and elsewhere. Here we only review briefly some key aspects.

Under the Type I extreme value distribution assumption for $\epsilon_{i j t}$, the market share for product $j$ in calendar year $t$ obtained from Eq.(2) is given by:

$$
s_{j t}=\frac{\exp \left(\delta_{j t}+\mu_{i j t}\right)}{1+\sum_{k=1}^{J} \exp \left(\delta_{k t}+\mu_{i k t}\right)}=\int_{v} \frac{\exp \left(\delta_{j t}+\mu_{i j t}\left(v_{i}, \ldots, ; \theta_{2}\right)\right)}{1+\sum_{k=1}^{J} \exp \left(\delta_{k t}+\mu_{i k t}\left(v_{i}, \ldots ; \theta_{2}\right)\right)} P(v) d v
$$

where $P(v)$ is the joint distribution over all elements of $v_{i}$, i.e., the product of standard normals. The integral in Eq.(7) does not have a closed form, and is evaluated using simulation, drawing values from the distribution of $v$ for a sample of individuals. The estimation of the model proceeds as follows. For a given draw of $\theta_{2}$, actual ${ }^{6}$ and predicted (Eq.7) market shares are equated by means of a contraction mapping that allows us to obtain a unique solution for $\delta_{j t}$, which is in turn used to compute the value of $\xi_{j t}$, or more precisely, $\xi_{j t}(\theta)$ (inner loop). Let $Z$ denote the available instruments. The sample analogs to the moment

\footnotetext{
${ }^{5}$ Note, however, that omitted brand effects may still be playing an important role. Not being able to fully account for this aspect is a limitation of our data. We provide a number of robustness checks along with an in-depth discussion of the role brand in section 5.4.

${ }^{6}$ Market shares are obtained by dividing actual sales by the market size. As in most previous studies, we define the market size as being the number of households in the U.S. for a given year. Data on the number of households was obtained from the U.S. Census Bureau (available at http://www.census.gov).
} 
conditions $E[\xi Z]=0$ can thus be constructed by using $\xi(\theta)$. An outer loop searching for the parameters $\hat{\theta}$ that solve the minimization of the GMM objective function completes the estimation routine (i.e., $\left.\hat{\theta}=\arg _{\theta} \min \xi(\theta)^{\prime} Z \Phi^{-1} Z^{\prime} \xi(\theta)\right)$. Here, the weighting matrix $\Phi$ is a consistent estimate of $E\left[Z^{\prime} \xi(\theta) \xi(\theta)^{\prime} Z\right]$, and is obtained employing the usual two-stage procedure (see Nevo 2000 for more details). Finally, as noted by Knittel and Metaxoglou (2014), the estimation procedure is subject to variability depending on the optimization algorithms and initial values considered. Similarly, Dube et al. (2012) note the dangers of using loose tolerance levels in the estimation procedure. Consistent with best practices recommended in both cases, we use multiple optimization algorithms, 50 different starting values, and best-practice tolerance levels in our implementation ${ }^{7}$.

\section{Empirical analysis}

\subsection{Main effects model}

Our specification for $x_{j t}$ builds upon existing literature, using variables similar to those used by Berry et al. (1995), Sudhir (2001) and Balachander et al. (2009). We include the variables SIZE, HPWT, and MPD as product characteristics in $x_{j t}$. We also include in $x_{j t}$ dummy variables to indicate whether a model year is from the previous year (PREVY_MY) or the next year (NEXTY_MY), dummy variables to indicate whether the model was launched in the last 2 years (INTRO2Y) or is soon (2 years) to be out of the market (EXIT2Y), and a time trend (TREND). In terms of the additional brand-level variables $x_{b t}$, we include dummy variables for manufacturer region (MANUF_EUR, MANUF_ASIA; MANUF_USA is the excluded category).

We start our discussion of the results with the estimation of the main effects model (Eq. 5). The random coefficients model -which allows for customer heterogeneity and accounts for the endogeneity of prices and warranties- is obtained by performing the estimation procedure described in section (4.3). ${ }^{8}$ If customer heterogeneity is ignored (i.e. $\mu_{i j t}=0$ ), the model (Eq. 3) can be estimated by OLS regression (if the endogeneity of prices and warranties is not accounted for) or by using instrumental variable techniques (e.g. 2SLS). We refer to the latter case as IV LOGIT. Table 3 displays the results obtained in each of the aforementioned cases.

The results in Table 3 show that the coefficient for the price moves in the expected

\footnotetext{
${ }^{7}$ We use five optimization methods: two quasi-newton methods, nelder-mead simplex, solvopt and conjugate gradient. Also, we use tolerance levels of $e^{-14}$ for the inner loop and $e^{-6}$ for the outer loop.

${ }^{8}$ In our implementation, we include random coefficients for variables for which we observe most substantial variation at the make-model level, i.e. PRICE, HPWT, SIZE and MPD.
} 
direction, i.e., demand becomes most sensitive to price as the price endogeneity is accounted for. Indeed, sensitivity to price more than doubles, similar to the findings in Berry et al. (1995) and Petrin (2002). Similarly, the coefficient of the warranty variable has a negative sign in the OLS regression (-0.034). However, once the endogeneity of the warranty length is accounted for using the instrumental variables described in the discussion of our identification strategy (IV LOGIT and Random coefficients model), we obtained a positive and significant effect of warranty length on demand ${ }^{9}$. Note that the fact that a positive coefficient for warranty (0.082 in the random coefficients model, 0.132 in the IV LOGIT) is only obtained after correcting for the endogeneity of the warranty variable and that a negative coefficient is obtained otherwise, is consistent with a scenario in which brand reputation (which is part of the unobservable) is negatively correlated with the warranty length, which in turn explains the bias in the warranty coefficient if we do not employ our strategy for endogeneity correction. Other variables with a significant effect on demand are PQ, HPWT, SIZE, and dummy control variables for vehicle model year, manufacturer region (significant effect for European automakers only), model exit, and the time trend. The results displayed for the random coefficients model also include the magnitude of the estimates for the heterogeneity parameters, which indeed reveals significant heterogeneity effects for price, the horsepower to weight ratio, and the vehicle size.

\footnotetext{
${ }^{9}$ We also estimated the model accounting only for the endogeneity of price, ignoring the endogeneity of warranty length (not reported in the text). We obtained a negative coefficient of warranty length in that case.
} 
Table 3: Estimation of the main effects model

\begin{tabular}{|c|c|c|c|c|c|c|c|c|}
\hline \multirow{3}{*}{ Variable } & \multirow{2}{*}{\multicolumn{2}{|c|}{ OLS }} & \multirow{2}{*}{\multicolumn{2}{|c|}{ IV LOGIT }} & \multicolumn{4}{|c|}{ RANDOM COEFFICIENTS MODEL } \\
\hline & & & & & \multicolumn{2}{|c|}{ Main effects } & \multicolumn{2}{|c|}{ Heterogeneity } \\
\hline & Estimate & Std.Err. & Estimate & Std.Err. & Estimate & Std.Err & Estimate & Std.Err. \\
\hline PRICE & $-0.035^{* * *}$ & 0.003 & $-0.083^{* * *}$ & 0.010 & $-0.096^{* * *}$ & 0.010 & $0.028^{* * *}$ & 0.006 \\
\hline WARR & $-0.034^{*}$ & 0.018 & $0.132^{* * *}$ & 0.049 & $0.082^{*}$ & 0.048 & & \\
\hline PQ & $0.670^{* * *}$ & 0.168 & $0.755^{* * *}$ & 0.186 & $0.950^{* * *}$ & 0.183 & & \\
\hline $\mathrm{SQ}$ & $-7.038^{* * *}$ & 1.449 & 1.193 & 2.257 & 0.069 & 2.126 & & \\
\hline HPWT & 0.059 & 0.298 & $4.369^{* * *}$ & 0.905 & $2.319^{* *}$ & 0.941 & $0.729^{* * *}$ & 0.249 \\
\hline SIZE & $1.625^{* * *}$ & 0.257 & $3.245^{* * *}$ & 0.422 & $2.497^{* * *}$ & 0.440 & $0.436^{* * *}$ & 0.118 \\
\hline MPD & -0.169 & 0.138 & $0.302^{*}$ & 0.180 & -0.110 & 0.227 & 0.131 & 0.194 \\
\hline NEXTY_MY & $-2.64^{* * *}$ & 0.075 & $-2.652^{* * *}$ & 0.083 & $-2.654^{* * *}$ & 0.089 & & \\
\hline PREVY_MY & $-1.885^{* * *}$ & 0.063 & $-1.928^{* * *}$ & 0.071 & $-1.916^{* * *}$ & 0.060 & & \\
\hline INTRO2Y & 0.089 & 0.090 & 0.115 & 0.100 & 0.103 & 0.094 & & \\
\hline EXIT2Y & $-0.891^{* * *}$ & 0.123 & $-0.943^{* * *}$ & 0.136 & $-1.015^{* * *}$ & 0.132 & & \\
\hline TREND & $-0.042^{* *}$ & 0.019 & $-0.152^{* * *}$ & 0.030 & $-0.265^{* * *}$ & 0.037 & & \\
\hline MANUF_EUR & 0.057 & 0.106 & $1.209^{* * *}$ & 0.260 & $0.907 * * *$ & 0.252 & & \\
\hline MANUF_ASIA & -0.101 & 0.077 & -0.049 & 0.110 & -0.034 & 0.103 & & \\
\hline CONSTANT & -1.844 & 1.533 & $-13.135^{* * *}$ & 2.765 & $-8.626^{* * *}$ & 2.839 & & \\
\hline
\end{tabular}

With respect to the estimation of the random coefficients model, as noted in section 4.3, we use different optimization algorithms and starting values. The reported solution in Table 3 is the one for which the value of the GMM objective function is minimized (equal to 169.1 in this case), and satisfies both first and second order conditions of optimality (i.e. zero gradient and positive-definite Hessian $)^{10}$. Most important, the results of the main effects model illustrate the effect of the instruments used in estimation, which act to adjust the price and warranty coefficients in the expected direction. In the first stage of the 2SLS procedure, the test for excluded instruments leads to rejection of the null hypotheses of excluded instruments having no explanatory power both in the case of PRICE and WARR (pvalue $<0.0001$ in both cases), with $R^{2}$ and $F$ statistic of 0.78 and 222.7 in the case of PRICE, and 0.44 and 50.5 in the case of WARR, respectively. The underidentification test also leads to rejecting the null of underidentification ( $\mathrm{p}$-value $<0.0001$, Anderson LM statistic $=146.7$ ). Overall, the model has desirable statistical properties and the tests performed support the use of our instruments.

\footnotetext{
${ }^{10}$ The estimation procedure arrives at the same optimal solution in $52 \%$ of the runs, which is in the order of magnitude of recent reports, e.g. Knittel and Metaxoglou (2014) and Dube et al. (2012), and is aligned with their findings about the need to use multiple starting values, optimization algorithms, and tight tolerance levels.
} 


\subsection{Model with complementarities}

The model in the previous section is useful to study the main effects of our variables of interest and to illustrate the way in which our instrumentation strategy works. As noted earlier, however, we are also interested in investigating complementarities/substitution effects between service attributes and product quality. We now turn to the discussion of the results of the model involving two-way interactions between warranty length, service quality and product quality. We "mean center" the variables involved in interaction terms (WARR, $\mathrm{PQ}$ and $\mathrm{SQ}$ ), i.e. we subtract the mean from each individual observation, such that the individual coefficients for the single terms of these variables reflect the effect when the other two variables are set to their average values. The results of the random coefficients model are displayed in Table 4.

The GMM function in the optimal solution is 128.6 in this case, the solution satisfies both first and second order conditions for optimality, and the estimation procedure led to the reported optimal solution in $52 \%$ of the runs. Similarly to the main effects case, the model and the instruments have desirable statistical properties. In the first stage of the 2SLS procedure, the test for excluded instruments leads to rejection of the null hypotheses of excluded instruments having no explanatory power in all cases of PRICE, WARR, WARRxPQ, WARRxSQ (p-value $<0.0001$ in all cases), with $R^{2}$ and $F$ statistic of 0.78 and 217.8 in the case of PRICE, 0.45 and 50.1 for WARR, 0.27 and 22.6 for WARRxPQ, and 0.21 and 16.7 for WARRxSQ, respectively. The underidentification test leads to rejecting the null of underidentification (p-value $<0.0001$, Anderson LM statistic $=113.9$ ).

The negative and significant coefficient for the interaction term WARRxPQ indicates that the marginal effect of an additional year of warranty coverage on demand decreases with product quality, or, conversely, is higher when product quality is lower. A longer warranty acts as a partial substitute for product quality, which is consistent with the insurance role of warranties. Similarly, we obtain a negative and significant coefficient for the term PQxSQ. Noting that the effect of service quality is not significant when treated in isolation in the main effects model (Table 3), this result suggests that service quality is of value for consumers mainly when the product quality is low. Jointly, these results provide support for the compensatory role of service attributes with respect to product quality, ruling out potential complementarities between product and service attributes in the demand function. In contrast, we obtain a positive and significant coefficient for the term WARRxSQ, indicating that the marginal effect on demand of an additional year of warranty coverage increases with service quality, i.e. there is a complementary relationship between the length of the warranty and service quality. 
Table 4: Estimation of the model with complementarities (Random coefficients model)

\begin{tabular}{lllll}
\hline \multirow{2}{*}{ Variable } & \multicolumn{3}{l}{ Main effect } & \multicolumn{3}{c}{ Heterogeneity } \\
\cline { 2 - 5 } & Estimate & Std.Err. & Estimate & Std.Err. \\
\hline PRICE & $-0.101^{* * *}$ & 0.011 & $0.035^{* * *}$ & 0.006 \\
WARR & $0.142^{*}$ & 0.079 & & \\
PQ & $1.369^{* * *}$ & 0.326 & & \\
SQ & -2.123 & 3.089 & & \\
WARR x PQ & $-1.217^{* * *}$ & 0.331 & & \\
WARR x SQ & $7.465^{* * *}$ & 2.871 & & \\
PQ x SQ & $-29.236^{* * *}$ & 6.943 & & \\
HPWT & 1.021 & 1.071 & $1.119^{* * *}$ & 0.291 \\
SIZE & $2.204^{* * *}$ & 0.527 & $0.353^{* * *}$ & 0.106 \\
MPD & $-0.562^{*}$ & 0.330 & 0.318 & 0.233 \\
NEXTY_MY & $-2.728^{* * *}$ & 0.093 & & \\
PREVY_MY & $-1.889^{* * *}$ & 0.064 & & \\
INTRO2Y & 0.058 & 0.098 & & \\
EXIT2Y & $-0.982^{* * *}$ & 0.147 & & \\
TREND & $-0.341^{* * *}$ & 0.045 & & \\
MANUF_EUR & $0.708^{* *}$ & 0.310 & & \\
MANUF_ASIA & -0.048 & 0.107 & & \\
CONSTANT & $-7.281^{* * *}$ & 1.314 & & \\
******,Significant at the $0.1,0.05,0.01$, confidence levels, respectively.
\end{tabular}

\subsection{Discussion}

Our results indicate that warranties have a significant effect on consumer demand, and that the marginal value of an additional year of warranty decreases with product quality and increases with service quality. Our estimates reveal that the median implied willingness to pay for an additional year of warranty, obtained as the ratio of the marginal utility of warranty length to the marginal disutility of price, is approximately $\$ 850$ which is equivalent to about $3.1 \%$ of the median vehicle price in our sample. This estimate seems reasonable by industry standards. Indeed, a comparable number was quoted in a recent industry report which mentioned that "consumers pay about 2 percent of the vehicle price per year of extended service" (Consumer Reports 2008).

Also, if we focus on the mean consumer utility, we note that, for a car with median product characteristics in our sample, the effect on consumer utility of a $1 \%$ price decrease is equivalent, all else being equal, to increasing product quality by $2.2 \%$, and is in turn equivalent to increasing the warranty length by $8 \%$. These benchmarks are useful for understanding the relative impact of different managerial interventions with respect to consumer demand. Indeed, these demand estimates can inform managerial decision-making by al- 
lowing managers to anticipate the effect of alternative interventions on consumer demand, which together with their usually good knowledge about the costs involved for each of these interventions, could be used to quantify trade-offs involved in managerial decision-making regarding these variables.

Further analysis of our model also reveals that median elasticities across manufacturers are -2.3 and 0.6 for price and warranty respectively (for product quality and service quality medians are 2.2 and 0.5 , respectively). Moreover, our estimates indicate that warranties play a more important role for U.S. manufacturers than for foreign firms during our period of analysis. Indeed, median implied warranty elasticity is about $50 \%$ higher for U.S. than for non-U.S. manufacturers, and similarly willingness to pay for warranties is larger for American brands. Our analysis provides an explanation for the higher relevance of warranties for American cars, i.e., that U.S.-based manufacturers had on average lower product quality and higher service quality than their foreign counterparts in that period. According to the results of our model, both of these factors imply a higher marginal effect of warranty length on consumer demand.

To summarize, warranties act as substitute for product quality, and as complement to service quality. As an illustration, if we split our sample into high (upper 50\%) and low (bottom 50\%) product quality and service quality, we observe that the highest demand response to warranty is obtained in the low product quality/high service quality region, where demand is actually elastic with respect to warranties, while the impact is lower when product quality is high and service quality is low. Indeed, warranty elasticity is approximately ten times higher in the low product quality region than in the high product quality region, and approximately twice as large in the high service quality region than in the low service quality region.

As further illustration of the implications of these results, let us consider, for example, the case of Kia, a brand that was characterized as having both low product quality and low service quality during our period of analysis. Having low product quality, and consistent with our result of warranties acting as substitutes for product quality, Kia increased the length of their powertrain warranty from 5 years/60,000 miles to 10 years/100,000 miles in 2001, i.e., the brand offered "America's No. 1 warranty". Our results imply that Kia would have benefited the most out of this great warranty coverage (in terms of the effect of this policy on consumer demand), if it had contemporaneously invested in providing better service quality, along with the warranty length increase. In short, being good at one service dimension (service quality) amplifies the effect of being good at another service dimension (warranty length), and the demand effect of both service attributes is higher when product quality is lower. 


\subsection{Robustness}

We now discuss some of the relevant modeling choices and examine the robustness of our main findings with respect to variations in some model constructs. Tables 5 and 6 display the results obtained for some selected robustness checks discussed in this section, several others are discussed but not displayed due to space limitations. For ease of display, we only show results for the mean utility estimates and for a subset of covariates; all models referenced in this section refer to the ones in tables 5 and 6 unless otherwise noted.

First, in section 3, we discussed a number of reasons why we use the length of the powertrain warranty in years as our warranty variable. Using alternative definitions, we found our main findings to be robust if, for example, we consider miles instead of years (model 1), or if we consider a weighted average between powertrain and basic warranty as our warranty variable (model 2; the interaction WARRxSQ becomes insignificant with a p-value 0.13 ); the basic warranty has very low variation and partially dampens significance.

Another relevant issue is the definition of the product quality variable. Arguably, there is no perfect way to measure quality. We believe, however, that the metric of problems per vehicle based on the initial quality study by J.D. Power is a reasonable choice. Indeed this definition captures a relatively objective metric of product quality, that has been widely available in the past, and that has had lots of visibility for consumers historically. J.D. Power also publishes data on vehicle dependability, which measures quality problems after 3 years of ownership. We collected some of these data and found a high correlation (0.75) between the vehicle dependability metric and our initial quality variable, which suggest some consistency in both product quality metrics. Furthermore, we think that quality problems in the first three months of ownership may be much more disruptive than quality problems after three years, which is one reason to prefer the initial quality variable used in our study (in addition, considering initial quality instead of vehicle dependability allows us to perform the analysis with a larger sample size). Nevertheless, we estimated the model using the vehicle's 3-year dependability metric to construct the product quality variable (model 3), and found results that are largely consistent with our main results, with the exception of the significance of the coefficient for the WARRxSQ variable with a p-value of 0.11 .

As an additional test at this regard, we collected data from Consumer Reports that measures product quality (reliability ratings in a relative five-point scale) at the model level, as opposed to the brand-level product quality variable from JD Power. We report results for this test in model 4 , which also considers the quality variables lagged by one period ${ }^{11}$. As

\footnotetext{
${ }^{11}$ We use contemporaneous quality metrics in our main models. One reasonable alternative could be to use lagged variables if consumers consider looking at that information in their decision making process (something perhaps more likely in the case of Consumer Reports scores). The idea behind our choice of
} 
Table 5: Selected various Robustness checks - Estimates of mean utility coefficients

\begin{tabular}{lllllllll} 
& \multicolumn{2}{c}{$(1)$} & \multicolumn{2}{c}{$(3)$} & \multicolumn{2}{c}{$(4)$} \\
\cline { 2 - 9 } & Estimate & Std.Err. & Estimate & Std.Err. & Estimate & Std.Err. & Estimate & Std.Err. \\
\hline PRICE & $-0.101^{* * *}$ & 0.012 & $-0.099^{* * *}$ & 0.012 & $-0.084^{* * *}$ & 0.011 & $-0.113^{* * *}$ & 0.024 \\
WARR & $0.125^{*}$ & 0.066 & 0.119 & 0.112 & $0.135^{*}$ & 0.080 & 0.083 & 0.082 \\
PQ & $1.805^{* * *}$ & 0.369 & $1.363^{* * *}$ & 0.300 & $0.477^{* * *}$ & 0.146 & 0.038 & 0.062 \\
SQ & -4.416 & 3.048 & -3.331 & 2.889 & -0.507 & 3.120 & 0.210 & 0.292 \\
WARR x PQ & $-1.856^{* * *}$ & 0.415 & $-1.207^{* * *}$ & 0.408 & $-0.572^{* * *}$ & 0.171 & $-0.311^{* * *}$ & 0.105 \\
WARR x SQ & $9.788^{* * *}$ & 2.368 & 5.978 & 3.901 & 6.467 & 4.098 & $1.030^{* * *}$ & 0.316 \\
PQ x SQ & $-35.018^{* * *}$ & 8.100 & $-23.785^{* * *}$ & 6.261 & $-20.725^{* * *}$ & 4.203 & -0.081 & 0.136
\end{tabular}

Notes: (1): Powertrain warranty in (10,000's) miles instead of years; (2): combined powertrain/basic warranty variable; (3): $\mathrm{PQ}$ in demand specification measured using the problems per vehicle metric of J.D. Power's dependability study; (4) PQ measured by the model-level reliability rating from Consumer reports, quality metrics lagged by one period. * ${ }^{* *},{ }^{* *}$, Significant at the $0.1,0.05,0.01$, confidence levels, respectively.

can be seen, directionally we obtain results somewhat similar to our main models, with the exception of the interaction between product and service quality becoming non-significant. There is an important caveat regarding the models that use Consumer Report data though, which is that these data is only available for $60 \%$ of our sample (equivalent to $78 \%$ in terms of sales), which could introduce some undesirable selection bias in those estimates, in particular dismissing some of the variation in our data necessary for identification (even at a brand level, the limited sample dismisses almost $20 \%$ of the brand-years). In addition, Consumer Reports data is a relative measure of product quality on a 1-5 scale, in contrast to the JD Power metric which measures product quality in an absolute scale, a factor also influencing these results.

Another concern with the model specification is that the results could be driven by extreme data points. In particular, Saturn can be seen as the only clear example of a brand consistently having good service quality and low product quality. We run our models excluding observations from Saturn, obtaining similar results to our main specification (not reported). Similarly, one could postulate a three-way interaction effect among product quality, service quality and warranty, meaning that the two-way interaction effects postulated by our model could in turn be moderated by the remaining variable as a third factor. We extended our model specification by adding the three-way interaction term WARRxPQxSQ and our main findings remain robust to this variation (not reported).

contemporaneous metrics is that the quality metrics reflect the actual quality experienced by consumers and that this information is a good summary of the quality information for consumers in a given year. We do not postulate that consumers would look exactly at that information before making a purchase, but rather than in general terms they reflect reasonably well reality for consumers in a given period. 
Next, based on the exogeneity assumption for product quality and service quality, our identification strategy makes use of competitor's product quality and service quality as instruments, among several other instruments. We have argued extensively why in our static model of price and warranty competition these instruments are well justified. However, as a way to partially relax the impact of that assumption, we tested a model that does not include competitor's product quality and service quality as additional instruments obtaining very similar results (not reported), in particular, all our key coefficients remain significant.

Perhaps a more sensitive issue is the potential role of brand fixed effects as confounders. As noted in section 4.2, the level of variation in our warranty variable does not allow us to control for brand fixed effects in the usual way in the model specification. This is certainly a limitation of our data and a matter of concern in our analysis and in our identification strategy. We noted, however, that the warranty is not the only brand-level variable in our model, and indeed, we are including product quality, service quality and an indicator of the manufacturer region as brand level variables. We make the following two observations in this regard. First, note that omitted brand-level factors are part of the unobservable, and accordingly this is part of the reason behind our identification strategy for warranties, i.e., in our formulation we are implicitly accounting for them in the estimation of warranty effects.

Second, we collected some additional brand-level variables, like the number of dealers of each brand (obtained from Automotive News's market data books) and the brand age, and estimated our models including these variables in the model specification as a way to partially control for some brand effects not captured in the main formulation. Our main findings remained only partially robust to these variations (models 5-6). In particular, the complementarity and substitution patterns remain qualitatively mostly robust (with the exception of the interaction WARR*SQ in model 6), although some effects are quantitatively less strong in terms of effect size than in our main model. We also tested some logit models with instrumental variables including also brand-level random effects, and the results were largely robust to this variation, with the exception of the non-significance of the interaction between warranty and service quality (not reported).

Finally, as a perhaps more definitive test of the brand issue, and considering the impossibility of including brand fixed effects and our brand-level variables at the same time for all brands, we adopted a modified approach that partially addresses this issue. The approach is to include brand fixed effects (dummies) but only for brands for which we observe longitudinal variation in warranties (i.e., brands with at least one warranty change in the observation period). We tested two versions of this approach, i.e., including brand fixed effects for the subset of brands with longitudinal variation in warranties that were in the top 10 brands with most sales (model 7), and including brand fixed effects for all brands with longitudi- 


\section{Table 6: Selected Brand-Robustness checks - Estimates of mean utility coefficients}

\begin{tabular}{|c|c|c|c|c|c|c|c|c|}
\hline & \multicolumn{2}{|c|}{$(5)$} & \multicolumn{2}{|c|}{ (6) } & \multicolumn{2}{|c|}{$(7)$} & \multicolumn{2}{|c|}{$(8)$} \\
\hline & Estimate & Std.Err. & Estimate & Std.Err. & Estimate & Std.Err. & Estimate & Std.Err. \\
\hline PRICE & $-0.077^{* * *}$ & 0.013 & $-0.077^{* * *}$ & 0.014 & $-0.091^{* * *}$ & 0.012 & $-0.094^{* * *}$ & 0.013 \\
\hline WARR & 0.116 & 0.073 & 0.073 & 0.074 & $0.155^{* *}$ & 0.078 & $0.219 * *$ & 0.093 \\
\hline PQ & $0.971^{* * *}$ & 0.327 & $1.009^{* * *}$ & 0.295 & $0.862^{* * *}$ & 0.281 & $1.054^{* * *}$ & 0.355 \\
\hline SQ & -0.585 & 2.811 & -1.478 & 2.854 & 1.297 & 2.527 & 0.095 & 2.424 \\
\hline WARR $x$ PQ & $-0.956^{* * *}$ & 0.308 & $-0.909 * * *$ & 0.284 & $-0.742^{* *}$ & 0.298 & $-0.908^{* *}$ & 0.357 \\
\hline WARR x SQ & $4.875^{*}$ & 2.701 & 3.663 & 2.612 & $5.402^{*}$ & 2.895 & $6.942^{*}$ & 3.691 \\
\hline$P Q \times S Q$ & $-26.718^{* * *}$ & 6.593 & $-23.327^{* * *}$ & 7.057 & $-20.770^{* * *}$ & 7.074 & $-24.522^{* * *}$ & 7.776 \\
\hline NDEALERS & $0.201^{* * *}$ & 0.057 & $0.249^{* * *}$ & 0.064 & & & & \\
\hline
\end{tabular}

Notes: (5): Including NDEALERS (number of franchised dealers, measured in 1000's) in the model specification; (6) including both NDEALERS and brand age dummies; (7) Include brand dummies for all top 10 seller brands that have longitudinal variation in warranties; (8) Include brand dummies for all brands that have longitudinal variation in warranties. ${ }^{*}, * *, * * *$, Significant at the $0.1,0.05,0.01$, confidence levels, respectively.

nal variation in warranties (model 8). As can be seen in Table 6, our main results remain remarkably robust, in particular, the significance of the interactions remains quite strong (with the exception of WARR*SQ that in this case is significant only at the $10 \%$ level).

Overall, we believe that these robustness checks are useful in supporting our main results to the extent possible with our data. In the case of the role of brand in particular, if more granular data becomes available, e.g., at the dealer level, future research may further examine our findings in more detail. For example, if variation in services across different dealers can be exploited as a richer source of identification. More generally, our analysis is subject to usual limitations encountered when dealing with observational data and identification strategies based on instrumental variables. While it may be unrealistic to conduct controlled field experiments in multi-firm and multi-year settings under competition like the one we consider, perhaps future research could explore single-firm field experiments to test effects similar to ours without the need to rely on instruments-based identification.

\section{Conclusion}

We formulate and estimate a model to study the impact of service attributes on demand, and the moderating role of product quality in that relationship. We focus on after-sales services, and characterize the service strategy of a firm by both its warranty length and its after-sales service quality. Our results indicate that both service metrics are complementary, i.e., the better the service quality of a brand, the higher the marginal effect of offering longer 
warranties on demand, and vice versa. Thus, these two service attributes reinforce each other. In contrast, no complementarities are observed for service attributes and product quality, and after-sales services play, rather, a compensatory role with respect to product quality, i.e., the impact of both service variables on demand increases when product quality decreases. Collectively, our results suggest that competing on after-sales services is more effective (in terms of its effect on demand) for firms that have lower product quality, and that a firm that increases its warranty length would benefit most by simultaneously investing in improving its service quality if existing service quality is low.

These findings illustrate that firms would benefit by defining their product and service strategies jointly rather than independently, i.e. they show that the joint consideration of product and service is essential for the development of an effective competitive strategy. In particular, the positioning of a firm with respect to product/service quality dimensions directly influences the marginal effect of its warranty length on consumer demand. Our model thus also provides a tool for managers to evaluate the impact of offering different warranty lengths on consumer demand (for a given positioning in product quality and service quality), which if complemented with actual warranty cost data (which are internally available), would help companies to define optimal warranty levels. We believe that the demand-side estimates derived from our analysis constitute a critical missing component for managerial decisionmaking in practice, as managers are usually very good at estimating the implied costs of different managerial interventions, while demand effects are much more difficult to isolate.

Our analysis of the service strategy of firms focused exclusively on the in-warranty period. In practice, firm service strategies also include the out-of-warranty period, and the definition of the warranty length could have implications in the profits that firms derive from selling extended warranties. Modeling the interactions between in-warranty and out-of-warranty policies offers an avenue for future research. Also, our identification strategy requires the exogeneity of product quality and service quality in the demand specification, which, as noted, is justified given our static model in which firms compete on prices and warranties only. While appropriate to capture short-term effects, our model does not capture longer-term dynamic aspects involved in firm decision-making and consumer demand. The formulation of a dynamic model that endogenizes long-term effects of firm investment in product quality and service quality is thus a natural -and much more complex- extension of our analysis. Future research could also explore refinements to our model specifications. For example, the incorporation of data on demographics would allow including non-linear income effects in the model. Finally, to our knowledge this is the first paper to empirically study how firm service strategies interact with product quality in a demand model of firm competition. The formulation of similar studies in other manufacturing industries would allow for a broader 
understanding of the value of services as part of firms' competitive strategies. We hope to conduct further research in these areas.

\section{Acknowledgement}

The authors are grateful for the suggestions made by the anonymous reviewers, associate editor, and department editor, and by the participants at the numerous conferences and universities where versions of this paper have been presented, including The Wharton School, Georgia Tech, University of Michigan, Harvard University, University of Maryland, Duke University, University of California Berkeley, Boston College, and The University of North Carolina. We would also like to thank Vibhanshu Abhishek and Paul Kleindorfer for their comments on earlier versions of this research, as well as Marcelo Olivares and Adam Copeland for facilitating some of the consumer reports data and pricing data. Guajardo acknowledges partial funding support by the Fishman-Davidson Center for Service and Operations Management, the Wharton Risk Center's Russell Ackoff Doctoral Student Fellowship, and the Wharton INSEAD alliance.

\section{References}

Allon, G., A. Federgruen. 2007. Competition in service industries. Operations Research, 55(1) $37-55$.

Allon, G., A. Federgruen, M. Pierson. 2011. How much is a reduction of your customers' wait worth? An empirical study of the fast-food drive-thru industry based on structural estimation methods. MSOM, 13(4) 489-507.

Automotive News. 2009. Chrysler drops lifetime warranty, (August 24), (accessed July 22, 2011), [available at http://www.autonews.com/article/20090824/RETAIL03/308249890]

Balachander, S., Y. Liu, A. Stock. 2009. An empirical analysis of scarcity strategies in the automobile industry. Management Science, 55(10) 1623-1637.

Bernstein, F., A. Federgruen. 2007. Coordination mechanisms for supply chains under price and service competition. MSOM, 9(3) 242-262.

Berry, S. 1994. Estimating discrete choice models of product differentiation. RAND Journal of Economics, 25(2) 242-262.

Berry, S., J. Levinsohn, A. Pakes. 1995. Automobile prices in market equilibrium. Econometrica, 63(4) 841-890.

Buell, R.W., D. Campbell, F.X. Frei. 2014. How do incumbents fare in the face of increased service competition? Working paper, Harvard Business School. 
Cachon, P.C., P.T. Harker. 2002. Competition and outsourcing with scale economies. Management Science, 48(10) 1314-1333.

Cachon, P.C., M. Olivares. 2010. Drivers of Finished-Goods Inventory in the U.S. Automobile Industry. Management Science, 56(1) 202-216.

Caplin, A., B. Nalebuff. 1991. Aggregation and imperfect competition: On the existence of equilibrium. Econometrica, 59(1) 25-59.

Chu, J., P. Chintagunta. 2009. Quantifying the economic value of warranties in the U.S. server market. Marketing Science, 28(1) 99-121.

Chu, J., P. Chintagunta. 2011. An empirical test of warranty theories in the U.S. computer server and automobile markets. Journal of Marketing, 75(3) 75-92.

Cohen, M.A., S. Whang. 1997. Competing in product and service: A product life-cycle model. Management Science, 43(4) 535-545.

Cohen, M.A., H. Lee, C. Cull, D. Willen. 2000. Saturn's Supply Chain innovation: High value in after-sales service. Sloan Management Review, 41(4) 93-101.

Cohen, M.A., N. Agrawal, V. Agrawal. 2006. Winning in the aftermarket. Harvard Business Review, 84(5) 129-138.

Cooper, R., T. Ross. 1985. Warranties and double moral hazard. The RAND Journal of Economics, 16(1) 103-113.

Consumer Reports. 2008. Extended warranties: A high-priced gamble, (April 2008), (accessed February 15, 2012), [available at http://www.consumerreports.org/cro/2012/05/extendedwarranties-a-high-priced-gamble/index.htm]

Copeland, A., W. Dunn, G. Hall. 2011. Inventories and the automobile market. The RAND Journal of Economics, 42(1) 121-149.

Crawford, G.S. 2012. Endogenous product choice: A progress report. International Journal of Industrial Organization, 30(3) 315-320.

Devaraj, S., K. F. Matta, E. Conlon. 2001. Product and service quality: The antecedents of customer loyalty in the automotive industry. Production and Operations Management, 10(4) 424-439.

Dieckmann, A., K. Dippold, H. Dietrich. 2009. Compensatory versus non compensatory models for predicting consumer preferences. Judgment and decision-making , 4(3) 200-213.

Douglas, E.J., D.C. Gelnnon, J.I. Lane. 1993. Warranty, quality and price in the US automobile market. Applied Economics, 25(1) 135-141.

Dube, J-P., J.T. Fox, C-L. Su. 2012. Improving the numerical performance of static and dynamic aggregate discrete choice random coefficients demand estimation. Econometrica, 80(5) 2231-2267.

Emons, W. 1989. The theory of warranty contracts. Journal of Economics Surveys, 3(1) 
$43-57$.

Fan, Y. 2013. Ownership Consolidation and Product Characteristics: A Study of the U.S. Daily Newspaper Market. American Economic Review, 103(5) 1598-1628.

Fisher, M.L., K. Ramdas, K.T. Ulrich. 1999. Components sharing in the management of product variety: A study of automotive braking systems. Management Science, 45(5) 297-315.

Gallino, S., G.P. Cachon, M. Olivares. 2013. Does adding inventory increase sales? evidence of a scarcity effect in us automobile dealerships. Working paper.

Gal-Or, E. 1989. Warranties as a signal of quality. The Canadian Journal of Economics, 22(1) 50-61.

Guajardo, J.G., M.A. Cohen. 2015. Quality differentiation in product-service bundles. Working paper.

Heal, G. 1977. Guarantees and risk-sharing. The Review of Economic Studies, 44(3) 549-560.

Knittel, C.R., K. Metaxoglou. 2014. Estimation of random-coefficient demand models: Two empiricists' perspective. Review of Economics and Statistics, 96(1) 34-59.

Lu, J-C., Y-C. Tsao, C. Charoensiriwath. 2011. Competition under manufacturer service and retail price. Economic Modelling, 28(3) 1256-1264.

Menezes, M.A.J., I.S. Currim. 1992. An approach for determination of warranty length. International Journal of Research in Marketing, 9(2) 177-195.

Mittal, V., P. Kumar, M. Tsiros. 1999. Attribute-level performance, satisfaction, and behavioral intentions over time: a consumption-system approach. Journal of Marketing, 63(2) 88-101.

Nevo, A. 2000. A practitioner's guide to estimation of random-coefficients logit models of demand. Journal of Economics \& Management Strategy, 9(4) 513-548.

Petrin, A. 2002. Quantifying the benefits of new products: The case of the minivan. The Journal of Political Economy, 110(4) 705-729.

Ramdas, K., T. Randall. 2008. Does component sharing help or hurt reliability? An empirical study in the automotive industry. Management Science, 54(5) 922-938.

Shaked, A., J. Sutton. 1982. Relaxing price competition through product differentiation. The Review of Economic Studies, 49(1) 3-13.

Shankar, V., L. Berry, T. Dotzel. 2009. A practical guide to combining products and services. Harvard Business Review, 87(11) 94-99.

So, K.C. 2000. Price and time competition for service delivery. MSOM, 2(4) 329-409.

Spence, M. 1977. Consumer misperceptions, product failure and producer liability. The Review of Economic Studies, 44(3) 561-572. 
Sudhir, K. 2001. Competitive pricing behavior in the auto market: a structural analysis. Marketing Science, 20(1) 42-60.

Thomas, M.U. 2006. Reliability and warranties: Methods for product development and quality improvement. CRC Press, Florida, USA.

Train, K.E., C. Winston. 2007. Vehicle choice behavior and the declining market share of U.S. automakers. International Economic Review, 48(4) 1469-1496.

Tsay, A.A., N. Agrawal. 2000. Channel dynamics under price and service competition. MSOM, 2(4) 372-391.

Warranty Week. 2006. Ford's powertrain warranties, (July 25), (accessed July 22, 2011), [available at http://www.warrantyweek.com/archive/ww20060725.html]

Warranty Week. 2011. Automotive warranty report, (April 7), (accessed July 22, 2011), [available at http://www.warrantyweek.com/archive/ww20110407.html]

Wiener, J. L. 1985. Are warranties accurate signals of product reliability? The Journal of Consumer Research, 12(2) 245-250. 